de enfermagem, de uma forma coerente, sem imposição cultural, fazendo com que o grupo planejasse, executasse e avaliasse a prática do cuidado. Os dados obtidos foram analisados seguindo o modelo do sol nascente. Seu uso é coerente e proporciona uma visão completa do mundo do cliente. O conhecimento das dimensões da estrutura social e cultural deuse através do conhecimento das várias estruturas que compõem essas dimensões. Durante a caminhada, o grupo falou sobre os fatores tecnológico, educacional, político e legal, religioso e filosófico, familiar e social, expressou seus valores culturais e estilo de vida, proporcionando condições para se compreender os padrões e expressões de cuidados e ao mesmo tempo identificar quais as práticas que poderiam ser mantidas, negociadas e repadronizadas, para que se efetivasse o cuidado de enfermagem culturalmente coerente. A aplicação dessa metodologia é possível, efetiva e gratificante, mas o profissional que deseja implementá-la terá que inicialmente repadronizar seus valores, reconhecer o grupo como um instrumento de cuidado, dentro de uma nova perspectiva, onde não há quem só cuide ou quem só é cuidado.

\title{
ENCONTROS E DESENCONTROS NA EXISTÊNCIA DAS MULHERES DURANTE O CLIMATÉRIO
}

\author{
WOMEN EXPERIENCING MENOPAUSE \\ ENCUENTROS Y DESENCUENTROS EN LA EXISTENCIA DE LAS MUJERES DURANTE EL \\ CLIMATERIO
}

Autora: Ivete Ghinato Dauod Orientadora: Maria da Glória Santana

RESUMO: Este estudo registra a minha inquietude ao percorrer novos caminhos na Enfermagem, refletindo os anseios da Mulher/Enfermeira, que vivencia o período do climatério. Trata-se de um trabalho realizado com um grupo de mulheres, durante o seu climatério, objetivando conhecer e compreender o seu pensamento com relação a essa etapa de suas vidas. Mediante a construção de um processo educativo embasado na minha experiência profissional, em alguns princípios da teoria Transcultural de Leininger, somados à teoria da problematização de Bordenave. Este estudo, de abordagem qualitativa, foi desenvolvido no Hospital Universitário $(\mathrm{HU})$, de Rio Grande. Os dados foram coletados em sete encontros com um grupo de mulheres, trabalhadoras ou não do HU, que espontaneamente optaram em participar da pesquisa. A depressão e a terapia de reposição hormonal surgiram como pontos chaves para a discussão do grupo e, a partir daí, delinearam-se os demais temas discutidos, que foram permeados pela ação do cuidado cultural, chegando-se na experiência das mulheres quanto a sua assistência à saúde no HU. As mulheres se reconhecem como sós, não encontrando a sintonia com a família e o companheiro; induzidas pela família a procurar auxílio para os seus anseios e angústias no âmbito profissional, não encontrando o que necessitam. As mulheres, apontam o processo educativo, onde o cuidar é fundamentado na interação entre a Enfermeira e a Mulher, como sendo um espaço naquela realidade, onde elas encontrariam a assistência necessária e desejada. A assistência de enfermagem à mulher durante o climatério requer um olhar a partir desta mulher, possibilitando assim o planejamento das ações do cuidado culturalmente congruente. A Enfermagem necessita rever a sua prática de assistência a essa mulher, enfocando-a como usuária do Sistema Único de Saúde, uma vez que a categoria ainda está voltada a atendê-la, principalmente, no seu período reprodutivo.

\section{GRUPOS DE CONVIVÊNCIA: DO MITO À REALIDADE NO CUIDADO DO CARDIOPATA}

\author{
COMPANIONSHIP GROUPS: FROM MYTH TO REALITY IN CARING FOR THE CARDIAC PATIENT
}

\section{GRUPOS DE CONVIVENCIA: DEL MITO A LA REALIDAD EN EL CUIDADO DEL CARDIOPATA}

Autora: Andréia Bendine Gastaldi Orientadora: Ymiracy N. de Souza Polak

RESUMO: Este estudo é o relato de uma prática assistencial desenvolvida junto a um grupo de cardiopatas que teve como objetivos: desenvolver uma prática de cuidado com cardiopatas, num grupo de convivência, alicerçado na concepção de 
educação de Paulo Freire e na compreensão de POLAK sobre o cuidado; socializar conhecimentos concernentes à prevenção de danos e limitações ao indivíduo cardiopata ; discutir e delinear estratégias de cuidado que permitam a esse indivíduo viver com a condição de cardiopata de forma digna. Os pressupostos que nortearam este estudo foram: o individuo cardiopata necessita dos cuidados de enfermagem na sua fase de hospitalização, anteriormente e posteriormente a ela; a prática educativa ajuda a entender melhor o processo saúde-doença e a melhor cuidar de si e da sua saúde; a convivência em grupos constituídos por individuos com a mesma condição de saúde, acrescida da troca de experiências, desenvolve potencialidades que ajudam no enfrentamento da cronicidade. Para tanto, foram delineadas estratégias de ação desenvolvidas em diferentes cenários e que culminaram com a formação de um grupo em uma Unidade Básica de Saúde. os resultados desta trajetória permitiram mostrar que o grupo é uma importante estratégia para o trabalho da enfermagem, porém constituise em um desafio que depende de algumas variáveis como: a política de saúde, a verticalização das ações de saúde, a cultura de cuidado vigente e, a assimilação, por parte dos clientes, dos valores vigentes referentes ao cuidado. Os temas emergentes do grupo e que caracterizam a condição de ser cardiopata foram caracterizados em: a temporalidade da doença, a descoberta do outro e organizando-se para viver melhor.

\title{
GRUPO OPERATIVO COMO ESTRATÉGIA PARA A ASSISTÊNCIA DE ENFERMAGEM: MULHERES EM DEPRESSÃO
}

\author{
OPERATIONAL TEAM AS A STRATEGY FOR GIVING NURSING ASSISTANCE TO WOMEN \\ SUFFERING FROM DEPRESSION
}

\section{GRUPO OPERATIVO COMO ESTRATEGIA PARA LA ASISTENCIA DE ENFERMERÍA: MUJERES CONDEPRESIÓN}

Autora: Débora Vitória Alexandrina Lisboa Villela Orientadora: Sonia Barros

\begin{abstract}
RESUMO: A partir de nossa observação durante as experiências de ensino, e no entendimento de que mulheres deprimidas expressam conflitos decorrentes de vivência depressiva e de seu cotidiano e por isso necessitam de atenção optamos por eleger estas mulheres como objeto neste estudo. Este teve como finalidade oferecer um espaço para a expressão vivencial de mulheres em depressão. Espaço operacionalizado por meio da técnica de grupo operativo, no qual os elementos do estudo, centrados na tarefa, trocaram experiências e avaliaram sua participação nos grupos. Para compreender o vivencial dessas mulheres optou-se pela pesquisa qualitativa, utilizando-se como método a pesquisa ação, em que o pesquisador e o sujeito interagem durante a pesquisa. A problemática do estudo envolveu a hipótese de que se as mulheres com diagnósticos de depressão tivessem um espaço para discutir seus problemas e expressar seus sentimentos, não haveria uma melhora em seu quadro. Os sentimentos foram reportados por seis mulheres depressivas que participaram de oito reuniões do grupo operativo. Os grupos tiveram temas disparadores elaborados com base nos relatos dos sujeitos em reunião discussão grupal: 1 - "concepção do processo saúde-doença mental"; 2 - "rede familiar e social"; 3 - "Repercussões físicas e psíquicas da doença"; 4 - "atividades de vida diária"; 5 - "Agravantes da doença"; 6 - "Resistência ao tratamento"; 7 - "Percepção de melhora"; 8 - "Necessidade de Escuta". Para a análise da discussão grupal empregou-se a análise temática das falas dos sujeitos. Os grupos operativos foram analisados nas formas de crônicas que se constituíram na sintese das reuniões grupais. Ao final, as mulheres analisaram a qualidade da ação interventiva, o grupo operativo nas suas vidas e mostraram que elas encontraram um lugar onde poderiam verbalizar sentimentos sem serem repreendidas, fortaleceram-se com o mesmo indicando sua utilização para outras mulheres com problemas semelhantes.
\end{abstract}

\section{PROCESSO DE CUIDAR EM GRUPO À LUZ DE UM REFERENCIAL CULTURAL: A EXPERIÊNCIA DE UMA ENFERMEIRA COM MULHERES QUE TIVERAM CÂNCER DE MAMA}

\author{
THE PROCESS OF TEAM CARING BASED ON A CULTURAL REFERENT: THE EXPERIENCE OF \\ A NURSE WITH BREAST CANCER PATIENTS
}

